\title{
RANCANG BANGUN MESIN ROLL BENDING PIPA EVAPORATOR FREEZER KAPAL DENGAN MOTOR LISTRIK 1 HP
}

\author{
Sunarto, Sisworo, Anggri Zulian Prasojo \\ Jurusan Teknik Mesin, Politeknik Negeri Semarang \\ Jalan Prof. H. Sudarto, S.H. Tembalang, Semarang \\ Email : sunarto.polines@gmail.com
}

\begin{abstract}
Abstrak
Pada industri skala kecil masih banyak dijumpai teknologi penunjang produksi yang dijalankan secara manual, salah satunya yaitu mesin roll bending. Sehingga dibutuhkan inovasi terhadap alat yang sudah ada agar dapat bekerja lebih efisien. Penelitian ini adalah membuat mesin roll bending pipa galvanis dengan diameter maksimal 3/4 inci. Metode yang digunakan untuk membuat mesin ini adalah observasi, perancangan, pembuatan komponen, perakitan, dan pengujian. Observasi kami lakukan untuk mencari data-data dan melakukan perhitungan yang akan kami jadikan pedoman untuk merancang mesin. Setelah perancangan mesin selesai, proses pembuatan komponen dan perakitan kami lakukan di sebuah bengkel di kabupaten Pati. Dari hasil pengujian mesin roll bending ini memiliki spesifikasi antara lain : dimensi $700 \mathrm{~mm} \times 700 \mathrm{~mm} \times 950 \mathrm{~mm}$, menggunakan motor listrik 1 HP sebagai sumber daya sehingga tidak memerlukan tenaga manusia seperti pada alat roll bending manual, kapasitas produksi mesin 96 unit perhari..
\end{abstract}

Kata Kunci : "Mesin roll", "bending", "produksi", "efisiensi"

\section{Pendahuluan}

Dalam industri perikanan di Indonesia, ikan segar hasil tangkapan nelayan yang memiliki mutu tinggi sangatlah penting untuk memenuhi kebutuhan konsumsi masyarakat. Produk perikanan merupakan bahan makanan yang mudah rusak (perishable food products). Masalah yang dihadapi nelayan dan pemilik kapal saat ini yaitu menurunnya hasil tangkapan yang diakibatkan oleh lama waktu melaut. Meningkatnya lama waktu melaut dan kurangnya pengetahuan mengenai cara pengawetan ikan yang baik mengakibatkan kualitas mutu ikan menjadi menurun,. Salah satu metode pengawetan ikan yang biasa digunakan oleh nelayan di kapal adalah metode pendinginan.

Nelayan di Pelabuhan Perikanan Pantai (PPP) Bajomulyo menggunakan kapal berbahan kayu. Kapal yang digunakan memiliki ukuran GT (Gross Tonnage) yang berbeda-beda sesuai alat tangkap yang digunakan. TPI Bajomulyo ratarata didominasi oleh kapal purse seine yang terdiri dari purse seine dengan jenis pengawetan freezer yang terdiri dari 97 kapal, sistem manual dengan pengawetan es dan garam sebanyak 90 kapal, serta sistem pengangkut sebanyak 60 kapal. Kapal purse seine tersebut terbuat dari kayu merbau, kayu bengkirai dan kayu meranti batu. Pemilik kapal purse seine biasanya juga merupakan pemilik kapal pengangkut. Kapal pengangkut digunakan untuk membantu mengangkut hasil tangkapan dari kapal dengan sistem manual (menggunakan es dan garam) yang berada di tengah laut. Palka pada kapal purse seine dengan sistem pendinginan terbuat dari fiber dan dibuat kedap udara, kedap air, dan diberi insulasi panas. Masing-masing palka berjumlah 12-14 ruang palka dan setiap palka dibuat secara terpisah antara satu dengan yang lain. Pada palka kapal purse seine dengan sistem pendingin es dan garam konstruksinya hampir sama dengan pendingin freezer.

Palka ikan pada sistem pendingin freezer dinding palka dilengkapi dengan adanya pipa-pipa pendingin atau yang disebut pipa evaporator yang dibuat 
menyambung dari satu palka ke palka yang lain dengan tujuan untuk menyalurkan udara dingint dari mesin pendingin ke dalam palka. Setelah udara dingin memenuhi dan mampu menjaga suhu ikan agar tetap dingin. Cairan yang terdapat didalam pipa-pipa tersebut adalah freon R22. Refrigerant berfungsi menyerap panas dari produk atau ruangan yang direfrigerasi. Uap freon yang digunakan tidak berpengaruh dan tidak mengubah rasa, warna, atau tekstur dari ikan.

Pada proses pembuatan pipa evaporator perlu menggunakan proses bengkok atau bending. Material yang memerlukan proses bengkok adalah pipa galvanis yang berfungsi sebagai pipa evaporator pada freezer. Tetapi alat bending yang digunakan di lapangan masih sangatlah sederhana yaitu dengan menggunakan tenaga manusia. Melihat kondisi tersebut, kami melihat peluang untuk berinovasi dengan mengaplikasikan ilmu yang di terima di perkuliahan untuk membuat teknologi tepat guna yang berhubungan dengan proses roll bending untuk material tersebut.

\section{Perancangan Mesin}

Perancangan (design) mesin didefinisikan suatu kegiatan perancangan sebuah mesin dalam sebuah gambaran atau sketsa komponen-komponen menjadi sebuah mesin yang berfungsi, yang kemudian hasil sketsa tersebut dianalisa untuk menentukan bagaimana langkah kerja untuk penyelesaian rancangan tersebut. Jika hasilnya sudah memenuhi kriteria, kemudian dibuat prototype, sehingga dapat diketahui kekurangan dalam kekurangan dalam perancangan desain untuk menghasilkan produk yang berfungsi dengan baik, handal dan aman.

Tujuan perancangan mesin adalah untuk merumuskan rencana dan memenuhi kebutuhan tertentu atau untuk memecahkan masalah, jika perancangan menghasilkan sesuatu yang memiliki realitas fisik maka produk harus fungsional, aman, handal, kompetitif, dan dapat digunakan, dan berharga.

Tahapan Perancangan Mesin

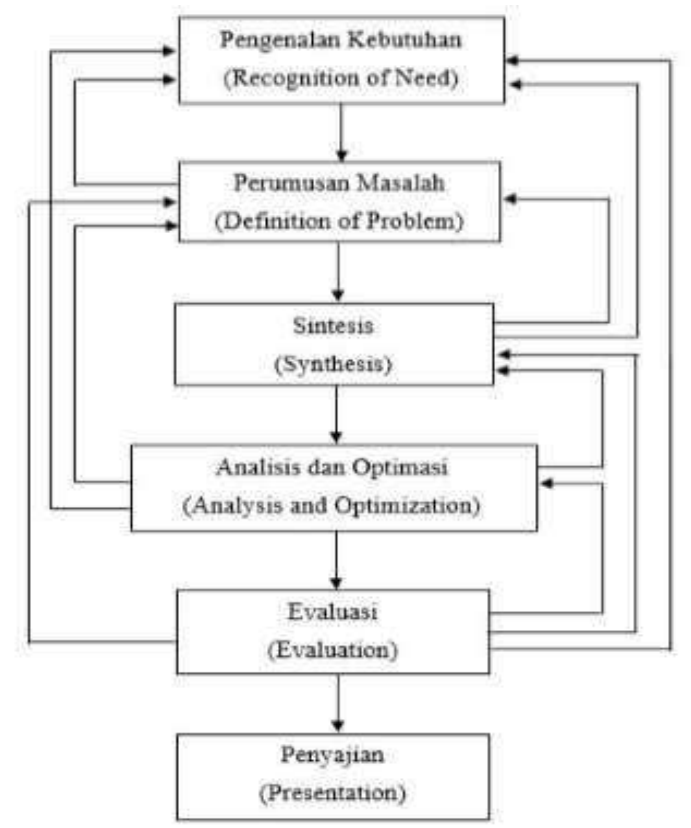

\section{Gambar 1. Tahapan Perancangan Mesin}

Proses perancangan dimulai dengan tahapan pertama yaitu tahap pengenalan kebutuhan (Recognition of Needs), dimana dalam tahapan ini berisi tentang alat yang diinginkan dan akan dibuat. Kemudian yang kedua dilanjutkan dengan tahap perumusan masalah (Definition of Problem), dimana dalam tahapan ini dilakukan proses perumusan masalah yang digunakan untuk memberikan arahan spesifikasi produk yang diinginkan. Tahap selanjutnya adalah sintesis (Synthesis) yaitu jawaban dari perumusan masalah yang digunakan untuk menentukan alternatif desain yang akan dibuat. Setelah sintesis dilakukan, maka dilanjutkan dengan tahap analisis dan optimasi (Analysis and Optimation), dimana tahap ini dilakukan proses perhitungan-perhitungan yang akan muncul untuk mengetahui apakah performa alat sudah sesuai dengan spesifikasi yang ditentukan. Evaluasi (Evaluation) adalah 
tahap dimana hasil sintesis dan analisis diukur terhadap spesifikasi yang telah ditentukan. Dalam tahap ini akan muncul desain yang terbaik.

\subsection{Desain yang Terpilih}

Dari alternatif desain yang ditawarkan di atas dengan membandingkan kelebihan serta kekurangan dari masing-masing desain maka dipilih desain I sebagai alternatif desain terbaik dengan memperoleh nilai 3,95. Artinya desain alternatif desain I memiliki nilai tertinggi dari penilaian yang telah ditentukan, sehingga alternatif desain I yang dipilih sebagai rancangan yang akan digunakan.

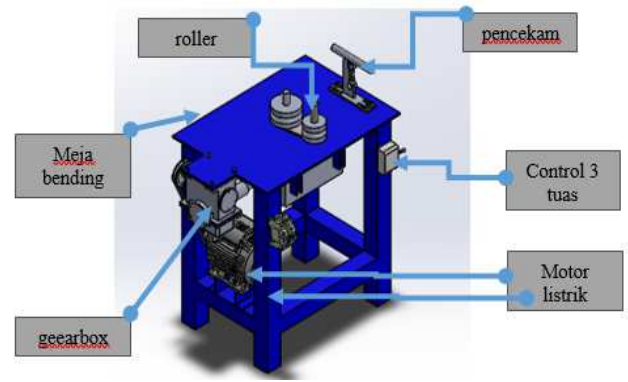

Gambar 2. Alternatif Desain

\subsection{Proses Pengujian}

Langkah-langkah pengujian adalah sebagai berikut :

1) Tancapkan steker ke stop kontak.

2) Posisikan saklar mcb ke posisi ON agar mesin siap digunakan.

3) Masukkan pipa yang akan dibengkokkan ke pencekam dan roller

4) Naikkan tuas untuk membengkokkan pipa.

5) Kembalikan tuas ke posisi tengah jika pipa sudah bengkok sesuai dengan sudut yang kita inginkan.

6) Turunkan tuas untuk mengembalikan roller ke posisi semula.

7) Ambil Pipa

8) Amati pipa dan catat hasil pembengkokkan sebagai data. Ulangi langkah di atas dengan pipa yang memiliki diameter berbeda.

9) Kembalikan sklar ke posisi OFF untuk mematikan sistem.

\section{Hasil Dan Pembahasan}

\subsection{Hasil Pengujian}

Hasil pengujian rancang bangun mesin roll bending pipa evaporator freezer kapal dengan motor listrik $1 \mathrm{HP}$ adalah sebagai berikut :

\section{Tabel 3.1 Data Pengujian}

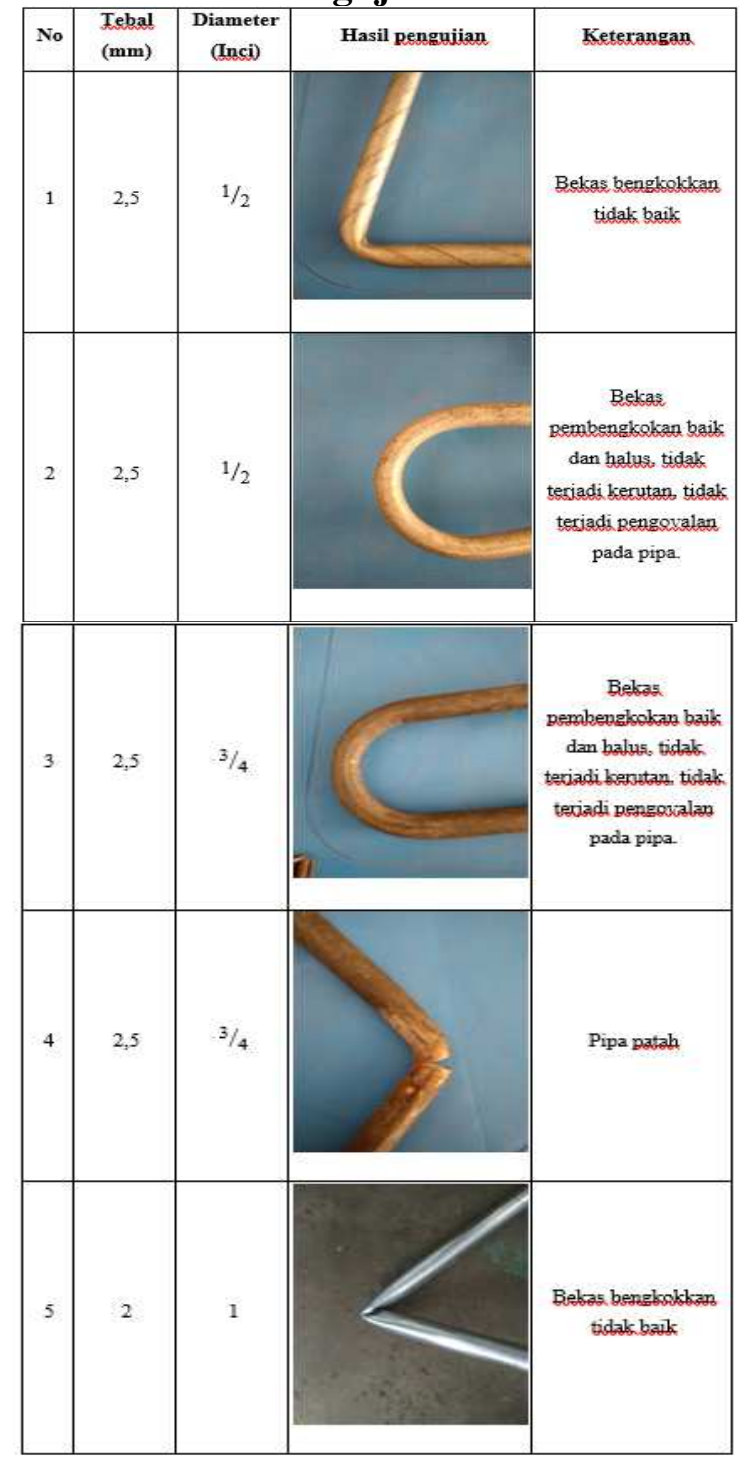

\subsection{Analisa Hasil Pengujian}

\section{Pengujian 1}

Pipa yang diuji berdiameter $1 / 2$ inci dengan ketebalan 2,5 mm hasil bengkokkan tidak baik dan pipa tidak bisa digunakan lagi. Hal 
ini diakibatkan karena pencekaman yang kurang maksimal, sehingga saat pipa dibengkokkan pipa bergeser dan tertarik.

\section{Pengujian 2}

Pipa yang diuji berdiameter $1 / 2$ inci dengan ketebalan 2,5 mm hasil pembengkokkan baik dan halus, tidak terjadi kerutan, tidak terjadi pengovalan pada pipa.

\section{Pengujian 3}

Pipa yang diuji berdiameter $3 / 4$ inci dengan ketebalan 2,5 $\mathrm{mm}$ hasil Bekas pembengkokkan baik dan halus, tidak terjadi kerutan, tidak terjadi pengovalan pada pipa.

\section{Pengujian 4}

Pipa yang diuji berdiameter $3 / 4$ inci dengan ketebalan 2,5 $\mathrm{mm}$ hasil pipa yang dibengkokkan patah pada sambungan las. Hal ini dikarenakan sambungan las tersebut menjadi tumpuan saat proses pengerolan, maka dari itu sebisa mungkin sebelum melakukan pembengkokkan kita meletakan pipa pada roller dengan sambungan las tidak pada titik tumpu pembengkokkan.

\section{Pengujian 5}

Pipa yang diuji berdiameter 1 inci dengan ketebalan $2 \mathrm{~mm}$ hasil bengkokkan tidak baik dan pipa tidak bisa digunakan lagi. Hal ini diakibatkan karena pipa memiliki ketebalan yang terlalu tipis .

\section{Kesipulan Dan Saran}

\subsection{Kesimpulan}

Rancang bangun mesin roll bending pipa evaporator freezer kapal dengan motor listrik $1 \mathrm{hp}$ ini memiliki dimensi $700 \mathrm{~mm}$ x $700 \mathrm{~mm}$ x $950 \mathrm{~mm}$. Sistem transmisi yang digunakan adalah gearbox dan vanbelt. Gearbox yang digunakan ada 2 buah. Menggunakan daya motor listrik sebesar 1 HP dengan kecepatan
1450 rpm. Menggunakan reducer untuk mereduksi putaran dan dilanjutkan ke gearbox dengan perbandingan 1:40 dan gearbox 1:100.

\subsection{Saran}

Adapun beberapa saran untuk langkah pengembangan danpenyempurnaan alat/mesin ini adalah:

1) Menambah roller dengan ukuran yang berbeda agar dapat digunakan untuk membengkokkan pipa dengan diameter yang lebih besar dari $3 / 4$ inci.

2) Menambah roller dengan radius yang berbeda.

3) Panjang lengan antar roller dibuat dapat diubah panjangnya.

4) Ketinggian roller dan pencekam dapat diatur.

\section{Daftar Pustaka}

- Cross, Nigel. 2005. Engineering Design Methods Strategies for Product Design. London : John Wiley \& Sons, Ltd.

- L.Mott, Robert. 2009. Elemen Mesin Dalam Perancangan Mekanis. University Of Dayton:Yogyakarta

- Seng, Lim Poh,Tay Seng Ho,Koh Kok Pin. 2008. Strength of Materials. Polytechnic Singapore: Singapore

- Sularso,Kiyokatsu Suga. 2002. Dasar Perancangan Dan Pemilihan Elemen Mesin. Pradnya Paramita: Bandung.

- R.S. Khurmi \& J.K Gupta, 2005. A Textbook of Machine Design. Eurasia Publishing House: New Delhi 